Article

\title{
Using VEGNET In-Situ Monitoring LiDAR (IML) to Capture Dynamics of Plant Area Index, Structure and Phenology in Aspen Parkland Forests in Alberta, Canada
}

\author{
Carlos Portillo-Quintero ${ }^{1}$, Arturo Sanchez-Azofeifa ${ }^{1, *}$ and Darius Culvenor ${ }^{2}$ \\ 1 Department of Earth and Atmospheric Sciences, University of Alberta, Edmonton, AB T6G 2E3, \\ Canada; E-Mail: portillo@ualberta.ca \\ 2 Environmental Sensing Systems, 16 Mawby Road, Bentleigh East, VIC 3165, Australia; \\ E-Mail: darius.culvenor@sensingsystems.com.au \\ * Author to whom correspondence should be addressed; E-Mail: arturo.sanchez@ualberta.ca; \\ Tel.: +1-780-492-1822; Fax: +1-780-492-2030.
}

Received: 4 March 2014; in revised form: 11 May 2014 / Accepted: 13 May 2014 /

Published: 22 May 2014

\begin{abstract}
The use of ceptometers and digital hemispherical photographs to estimate Plant Area Index (PAI) often include biases and errors from instrument positioning, orientation and data analysis. As an alternative to these methods, we used an In-Situ Monitoring LiDAR system that provides indirect measures of PAI and Plant Area Volume Density (PAVD) at a fixed angle, based on optimized principles and algorithms for PAI retrieval. The instrument was installed for 22 nights continuously from September 26 to October 17, 2013 during leaf-fall in an Aspen Parkland Forest. A total of 85 scans were performed ( $\sim$ scans per night). PAI measured decreased from 1.27 to 0.67 during leaf-fall, which is consistent with values reported in the literature. PAVD profiles allowed differentiating the contribution of PAI per forest strata. Phenological changes were captured in four ways: number of hits, maximum cumulative and absolute PAI values, time series of PAVD profiles and PAI values per forest strata. We also found that VEGNET IML Canopy PAI and MODIS LAI values showed a similar decreasing trend and differed by $2 \%-15 \%$. Our results indicate that the VEGNET IML has great potential for rapid forest structural characterization and for ground validation of PAI/LAI at a temporal frequency compatible with earth observation satellites.
\end{abstract}


Keywords: Leaf Area Index; ecosystem monitoring; ground LiDAR; vertical profile; hypertemporal

\section{Introduction}

The need for standardized and improved in-situ measurements of forest structural and compositional parameters is increasing. Surrogate indices and measures of structure and foliage density of a particular forested ecosystem are essential for monitoring an ecosystem's productivity, carbon storage capacity and ability to sustain its maximum levels of biodiversity. The use of Leaf Area Index (LAI) as a measurement of forest structure and productivity has been shown to produce satisfactory results for this matter [1-3]. Leaf area index (LAI) is a dimensionless variable and was first defined as the total one-sided area of photosynthetic tissue per unit ground surface area [4]. It is a measure of the amount of foliage and can be estimated relatively rapidly with optical instruments. The formal definition for LAI is the amount of foliage per unit surface area (projected one-sided LAI) [5]. Leaf Area Index is influenced by a range of factors such as seasonal climate, species composition and management practices [1] as well as biotic agents such as disease and insect herbivores [6].

LAI is a dynamic parameter and is driven by natural and anthropogenic processes at multiple spatial and temporal scales. Knowledge about the seasonal dynamics of foliage density through LAI measurements is important for modeling biosphere processes (e.g., water and carbon cycles) and understanding biological and physical processes in forests [7]. Moreover, shifts in temporal and spatial dynamics of forest phenology in temperate and tropical ecosystems have been suggested as being one of the impacts of climate change on global ecosystem functioning [8-10]. Monitoring LAI through time is therefore becoming of high interest for macroecological studies in the context of global change.

LAI measured through indirect methods (e.g., remote sensed vegetation indices, ceptometers, digital hemispherical photography) where leaf area is estimated from proximal measures, are usually faster to sample in the field and easier to process than direct methods (e.g., litterfall collection and processing). Such methods are practical for larger spatial scale assessments [1].

Current air- and space-borne methods are based on algorithms applied to spectral information collected in the visible and infrared portions of the spectrum at moderate to high spatial resolutions. Ground measurements through direct methods and indirect optical methods (e.g., ceptometers and digital hemispherical photography) are common for LAI estimation in the field. However, they are still considered labor intensive and highly subject to biases and errors for long term monitoring programs. LAI estimation based on traditional indirect methods also relies on assumptions regarding canopy heterogeneity (vertically and horizontally), clumping, canopy closure or gaps [11].

Over the past decade there has been a rapid development in portable Terrestrial Laser Scanners (TLS). The technology has proven highly useful for estimating total aboveground biomass and providing detailed vertical profiles of forest environments [3,12,13]. Terrestrial Laser Scanner measurements are generally mounted on a survey tripod about $1.5 \mathrm{~m}$ above the ground. The majority of TLS instruments sample the forest with a high spatial resolution (typically about half a centimeter between consecutive laser pulses) and a relatively small laser footprint size with respect to the typical dimensions of leaves 
and other tree organs [12]. When laser pulses emitted in the visible or near-infrared comes into contact with an object, part of that energy is reflected back toward the instrument and triggers the recording of its distance and intensity [12]. TLS systems typically employ vertical and horizontal scanning about a fixed point of observation, providing a hemispherical representation of biomass distribution in the forest leaves, branches and trunks, which allows exploring foliage angle distributions and clumping [3,13-15].

In recent years, research on LAI estimation has largely focused on the improvement of algorithms for its retrieval based on indirect methods and the addition of correction factors for the proper validation and derivation of global LAI models based on satellite imagery. However, one of the main challenges in LAI estimation is the identification of the causes of its variation, as well as the structural and physiological processes that influence its dynamics in different ecosystems. The need for hypertemporal information on indirect ground LAI estimates is especially important for understanding the physiological basis of LAI dynamics and improving validation techniques for remote sensing products.

As part of its program on vegetation monitoring, Australia's Commonwealth Scientific and Industrial Research Organisation (CSIRO) has developed a new experimental TLS named VEGNET. The VEGNET system is a solar-powered device for semi-permanent installation in the field and automated operation. The VEGNET system provides indirect measures of LAI at a fixed angle based on optimized principles and algorithms for LAI retrieval. This new type of TLS was designed as an alternative to the use of 3-D TLS devices which can be costly and require complex post-processing for LAI retrieval. The VEGNET instrument automatically scans the forest on a daily basis, producing a vertical foliage density profile at a temporal frequency compatible with earth observation satellites. Given its automated mode of operation and semi-permanent installation, the VEGNET instrument is described hereafter as an In-situ Monitoring Lidar (IML), being a sub-category of TLS instruments specifically designed for automated, long term monitoring. In this paper, we report results from a study to test the performance of this device to capture changes in LAI during the fall season in an Aspen Parkland forest in Alberta, Canada and provide insights on its performance and capabilities.

\section{Materials and Methods}

\subsection{Study Site}

We installed the IML system within the forested lands of the Ministik Bird Sanctuary located $48 \mathrm{~km}$ south-east of Edmonton, Alberta, Canada. The Minsitik Bird Sanctuary, a large area ( 7000 ha) of public land area, consists mainly of forest patches greater than 1-ha within a matrix of grasslands and wetlands [16,17]. Major vegetation types include Balsam Poplar (Populus balsamifera) and Trembling Aspen (P. tremuloides) forests, Bromus inermis-Poa pratensis grasslands and Threadleaf Sedge (Carex filifolia) wetlands. Forests are classified as Boreal Mixed-Wood, although homesteading (logging and clearing) in the early 1900s created characteristics more similar to those of Aspen Parkland [17]. The IML instrument was positioned in a forest patch of approximately 16 ha of continuous forest $\left(53^{\circ} 18^{\prime} 13.35^{\prime \prime} \mathrm{N}, 112^{\circ} 59^{\prime} 50.10^{\prime \prime} \mathrm{W}\right)$. 


\subsection{VEGNET IML Instrument}

The VEGNET IML instrument uses a phase-based laser rangefinder with a wavelength of $635 \mathrm{~nm}$. The laser beam is directed at a rotating prism that reflects the laser at a fixed angle of $57.5^{\circ}$ zenith or the "hinge angle" [15]. As described by [18], the hinge angle is the theoretically optimum sample angle at which estimates of leaf area are least sensitive to assumptions of leaf angle distribution.

The prism is designed to perform full rotations of $360^{\circ}$ azimuth at this fixed zenith angle (no vertical scanning motion). Both canopy "hits" and "gaps" are recorded to enable calculation of angular gap fraction or gap probability (Pgap) at each height where a leaf, trunk or branch was hit by the laser [3]. As with digital hemispherical photography, estimates from laser scanning are also subject to underlying assumptions of random spatial distribution of leaves and knowledge of the leaf angle distribution.

It is important to note that the IML method of LAI retrieval, just like all other indirect methods, does not estimate leaf area index, as the laser does not differentiate between forest structural elements. Therefore, the term Plant Area Index (PAI) is preferred if no correction to remove branches and stems is made. Hereafter, we will refer to LAI estimated by indirect methods, including IML, as PAI values.

The height at which the IML laser intercepts scattering elements within the canopy is calculated from the distance measured to the scattering object and the laser inclination angle $\left(57.5^{\circ} \mathrm{zenith}\right)$. The rangefinder within the instrument has a maximum range of $60 \mathrm{~m}$ from green foliage during night-time operation. At a scan zenith angle of $57.5^{\circ}$ this equates to a maximum effective monitoring height of $30 \mathrm{~m}$. While azimuth angle is recorded for each measurement, all laser measurements are treated aspatially for the purpose of estimating PAI.

The IML uses two microcontrollers to control the lidar, scan motion, data storage and wireless connectivity. The system acquires approximately 900 samples during a full scan. All scan data are acquired at night to improve the laser signal relative to background noise, thereby increasing the effective range of the lidar. The IML instrument is shown in Figure 1. It includes a tripod that supports a waterproof enclosure containing the laser rangefinder and the rotating prism (scan head) at approximate $1.5 \mathrm{~m}$ from the ground. The scan head includes an inclined right-angle prism for changing the laser beam direction from vertical at the rangefinder aperture to $57.5^{\circ}$ zenith at the IML aperture. The glass scan prism is protected from mechanical damage by an aluminum shroud, but the exterior optical surface of the prism remains exposed. This keeps the prism relatively clean from periodic rainfall and also reduces the likelihood of insects and spiders obscuring the aperture during extended deployments. It does however require over-sampling, temporally, because some scans will inevitably be weather-affected and unsuitable for analysis. The tripod-mounted IML sensor head is connected to a power control and data-recording enclosure that can be placed on the ground below the tripod. The system is powered by four 6-volt rechargeable batteries. Batteries can be automatically recharged using solar panels in the field.

The IML was deployed in the field on September 25, 2013. We installed an 80-watt solar panel facing south to allow maximum sun exposure and battery recharge during the day. We ran the instrument during 22 nights continuously from September 26 to October 17, 2013 during leaf-fall. We expected that PAI values estimated during this time could reflect the process of leaf shedding by canopy and understory vegetation. The IML was programmed to acquire four complete scans between $10 \mathrm{pm}$ and 5 am 
daily in order to maximize the laser signal-to-noise ratio and increase the likelihood of acquiring data under ideal weather conditions.

Figure 1. The VEGNET In-Situ Monitoring Lidar (IML) system deployed in the Aspen forest parkland study site, southeast Edmonton, AB, Canada; the rotating prism system directs the laser at $57.5^{\circ}$ zenith; The instrument was protected from large animals using aluminum fencing material.

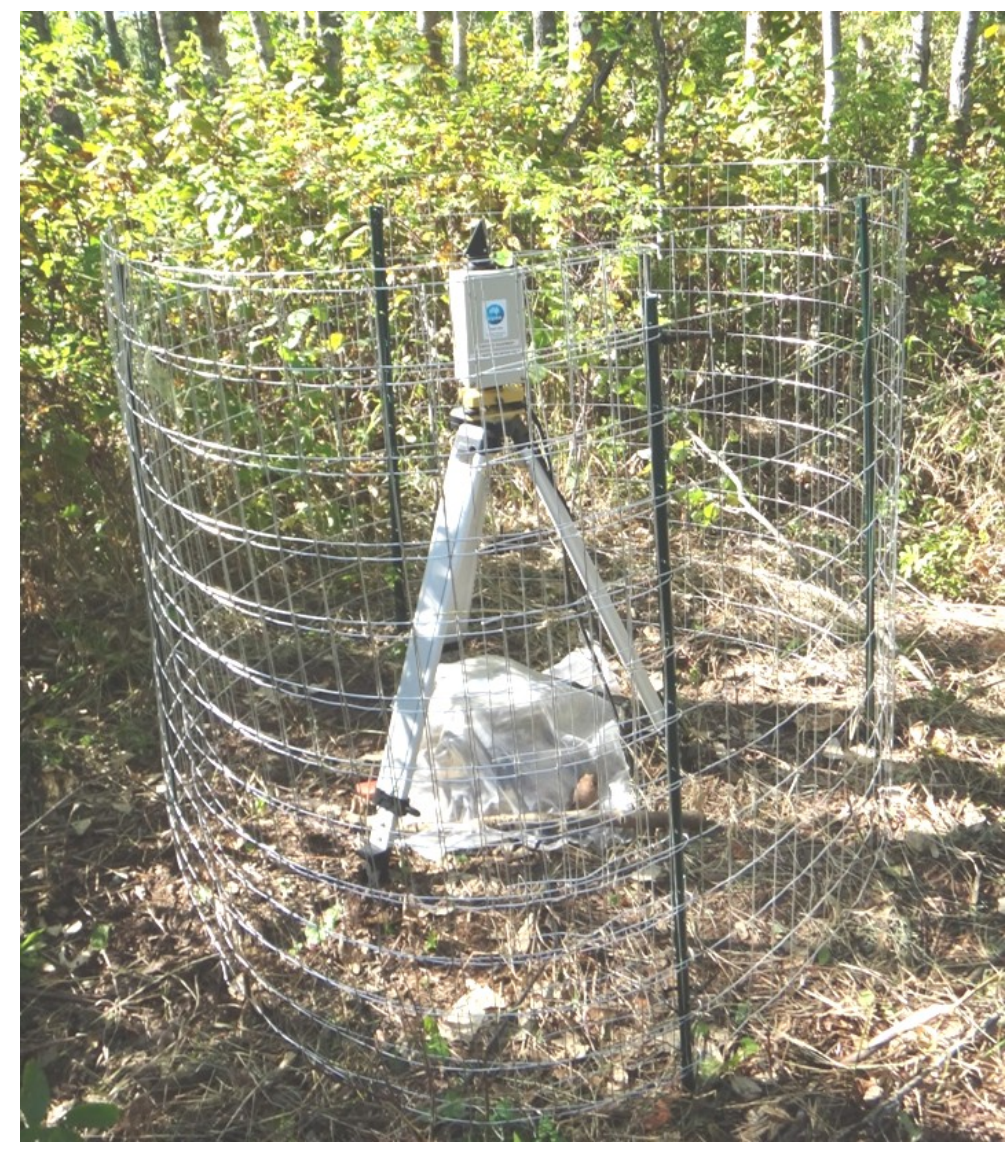

\subsection{Data Analysis}

Raw data are collected and stored on an internal memory card. These data are subsequently downloaded and processed to produce an estimate of Plant Area Index following methods by [3] and [15] for PAI retrieval based on LiDAR data. The PAI estimates are typically presented in three forms: (i) a cumulative PAI as a function of canopy height; (ii) the cumulative PAI derivative, termed the Plant Area Volume Density (PAVD); and (iii) the maximum cumulative PAI, which represents the top-of-canopy PAI, incorporating intercepted laser measurements through the full canopy depth.

We report and analyze trends in terms of the instrument performance and the PAI and PAVD values collected during the leaf-fall period, both for canopy and understory vegetation.

We also compared values obtained with LAI indirect measurements based on satellite imagery collected during the same time period. For this, we acquired data available during September 26 to October 17 from the Moderate Resolution Imaging Spectroradiometer (MODIS) Leaf Area Index composite product. MODIS LAI Values were obtained through the MODIS Land subsets online service (daac.ornl.gov). The MOD15A2 (Terra) LAI/fPAR (fraction of Photosynthetically Active Radiation) 
product is recorded at a nominal $1 \mathrm{~km}$ resolution and composited over 8 day temporal intervals. According to DeKauwe et al. [19], "the MODIS LAI/fPAR product is derived from an algorithm which compares the retrievals of daily surface reflectance at $1 \mathrm{~km}$ resolution with three dimensional radiative transfer model parameterised by varying biophysical parameters such as LAI and a solution to the inverse radiative transfer problem based on finding the 'best' matches in terms of RMSE" [19]. We compared and discuss our results by comparing IML estimates to MOD15A2 single pixel and $3 \times 3$ pixel window mean values. This comparison was performed in order to compare trends in time in leaf phenology dynamics and not for the validation of LAI/PAI values, since MODIS products are also prone to errors and biases as other indirect methods.

\section{Results}

\subsection{IML Performance}

The IML system executed a total of 85 scans of the forest from September 26 to October 17, 2013. It ran an average of four scans per night, with the exception of three scans that were performed during two nights and five scans on one night. During the time of data collection, the IML provided an average of $753 \pm 160$ records (successful pulses emitted) per scan for a total of 64,020 records, and an average of $438 \pm 128$ hits per scan for a total of 37,303 hits.

Figure 2 shows the trends in the number of records and hits during the 22 days of data collection. As noted in the figure, a sudden decrease in the number of records and hits was registered between September 31 and October 3 (Julian days 274-277 of 2013). We found that such a decrease can be explained by changes in local climatic conditions. By looking at data from the closest weather station (Approximately $10 \mathrm{~km}$ from the site) administered by the Alberta's Agricultural and Rural Development department [20], we found that two precipitation events occurred on September 29 and October 2 with maximum values of 0.8 and $0.6 \mathrm{~mm}$ of rain, respectively. A soil moisture sensor from a neighboring wireless sensor network, located at the site of deployment (approximately $3 \mathrm{~m}$ from the IML instrument), also registered an increase from October 1-3 when it peaked and then started to decrease. Figure 2 shows the trends in air Relative Humidity for the time of the data collection and an increase in air humidity from September 29 to October 3 is evident. Based on this information, we infer that a combination of direct rainfall and condensation on the scan prism resulted in an attenuating of light emission from the IML aperture, with a subsequent decrease in the amount of light pulses successfully emitted and forests elements hit. Because of this, data from October 1-3 was considered poor for PAI estimation and was excluded from further analysis.

Battery recharge through the use of a solar panel was successful during all the data collection period. Battery voltage remained stable with a registered average of $6.40 \pm 0.06$ volts per night and never dropping below 6.15 volts, which would cause the system to enter a hibernation mode until the batteries regained charge. 
Figure 2. Time-series of the number of records and hits registered by the VEGNET IML during September 26 and October 17, 2013.

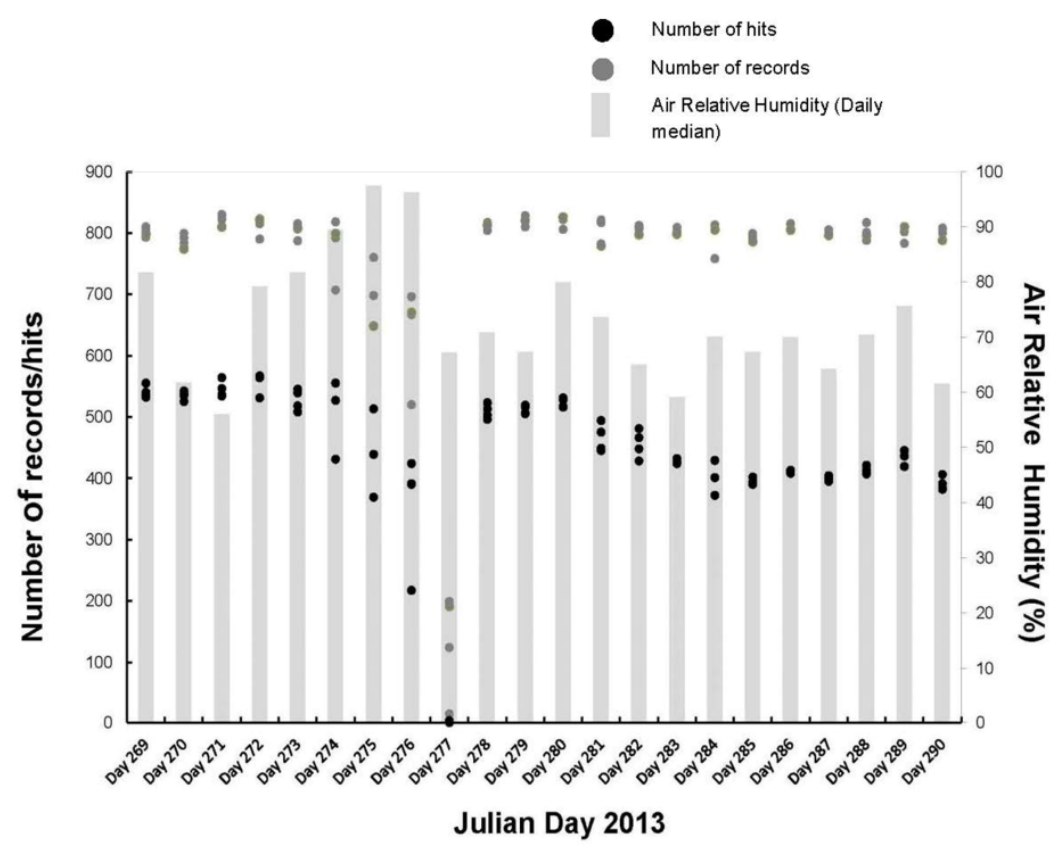

\subsection{Plant Area Index (PAI) and Plant Area Volume Density (PAVD)}

Figure 3 shows the time-series of PAI values calculated from VEGNET IML scans. Of these, three days of data collection were determined to be weather-affected and excluded from analysis. At first glance, the time-series shows a continuous decrease of PAI from Day 269 to Day 290. The highest maximum cumulative PAI measured was 1.27 on the Day 269, and the lowest maximum cumulative PAI measured was 0.67 on Day 290. During the first three days, the average value of PAI was $1.2 \pm 0.05$, which decreased to an average value of $0.8+0.06$ on the last three days of data collection. This corresponds to a $33 \%$ drop in PAI values.

Figure 4 shows the vegetation density profile (PAVD) at $0.1 \mathrm{~m}$ height increments, depicting the vertical distribution of plant biomass in the forest. Figure 4 also shows the time-series of PAVD values during the leaf-fall process.

The PAVD profiles show three height zones with higher density plant material. The three strata with high values of PAVD are located between 4-5 m, 6-7 m and 14-18 m respectively. The first stratum (4-5 m) corresponds to an understory vegetation layer that combines juvenile trees, shrubs and the trunks of canopy trees. The second stratum $(6-7 \mathrm{~m})$ corresponds to a layer composed by the branches and leaves of subcanopy trees along with the trunks of the canopy trees in the understory, while the third stratum $(14-18 \mathrm{~m})$ corresponds to leaves and branches of the overstorey canopy. The height values corresponding to the peaks of these strata occur at $4.8 \pm 0.18 \mathrm{~m}, 6.6 \pm 0.068 \mathrm{~m}$ and $16.3 \pm 0.86$. Average maximum height of a plant element registered by the instrument was $19.1 \pm 0.2$, which represents leaves and/or branches at the top of the canopy. 
Figure 3. Time-series of the maximum cumulative Plant Area Index (PAI) values calculated by the VEGNET IML during September 26 and October 17, 2013; boxplots show the variation of maximum cumulative PAI values from all scans performed in the same night.

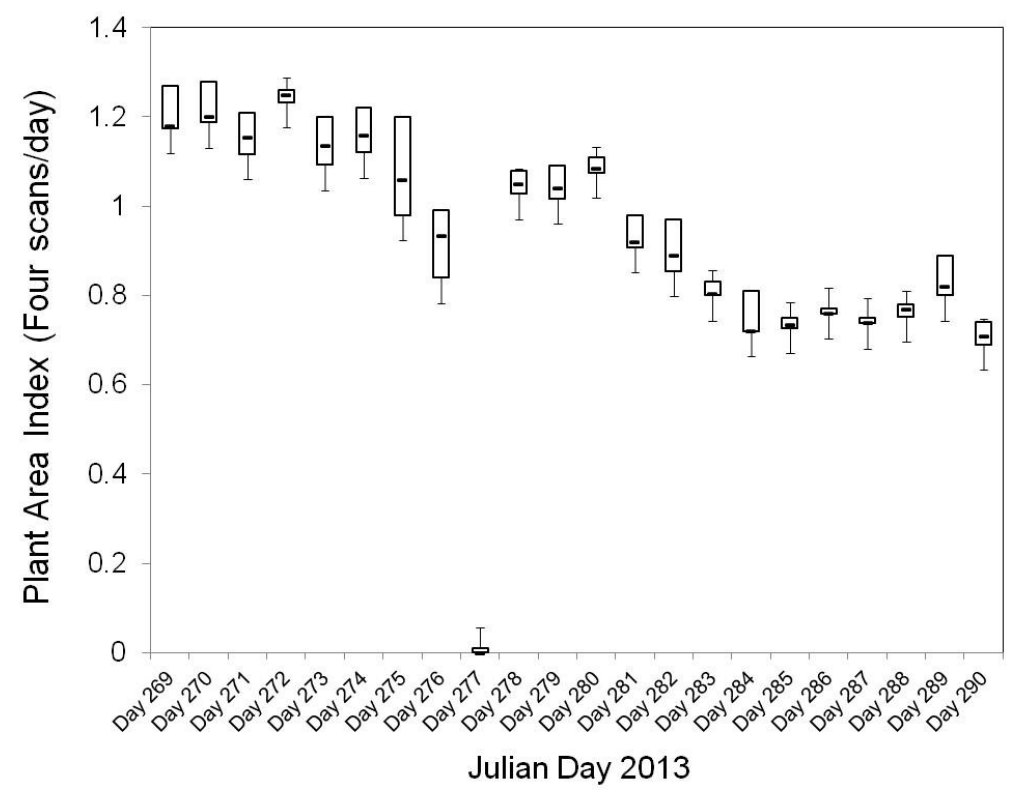

Figure 4. Time-series of Plant Area Volume Density (PAVD) values calculated by the VEGNET IML during September 26 and October 17, 2013; the volume density distribution is plotted against height in order to show the vertical distribution of biomass in the forest; values have been averaged by week for visualization purposes; three height strata with high PAVD values represent biomass concentration on the understory (trunks, shrubs, and juvenile trees), subcanopy (branches and leaves of subcanopy trees and trunks of the canopy trees in the understory) and canopy trees (canopy branches and leaves).

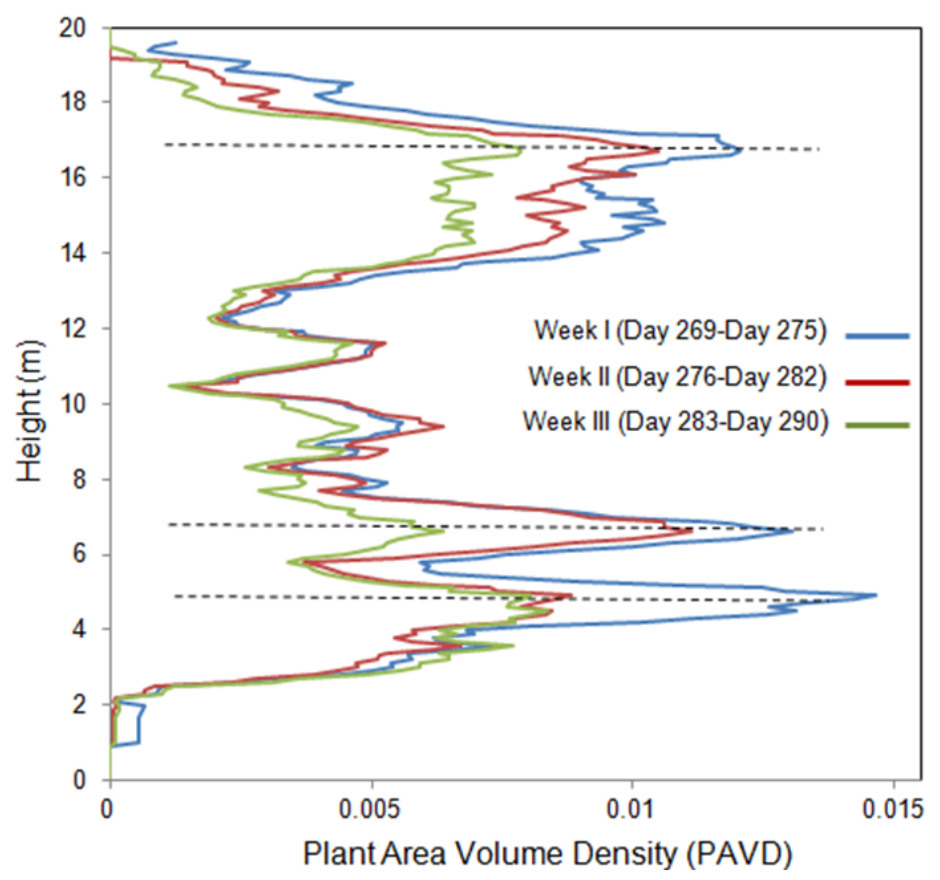


Based on these three height strata with high PAVD values, we plotted time-series of PAI values obtained according to three height ranges: $0-5.5 \mathrm{~m}, 5.5-10 \mathrm{~m}$ and $10 \mathrm{~m}$ to $20 \mathrm{~m}$. Figure 5 shows maximum cumulative PAI values for each height range, while Figure 6 shows total PAI values for each height range. Each data point in the figures represents an integrated PAI value calculated based on all scans performed on each night. As noted in both figures, PAI values from the understory layer are more stable and show little variation with time, while the subcanopy and canopy PAI values show a similar decreasing trend towards Day 290.

Figure 5. Time-series of maximum cumulative Plant Area Index (PAI) values calculated by the VEGNET IML during September 26 and October 17, 2013 for the understory, subcanopy (understory layer 2), and Canopy.

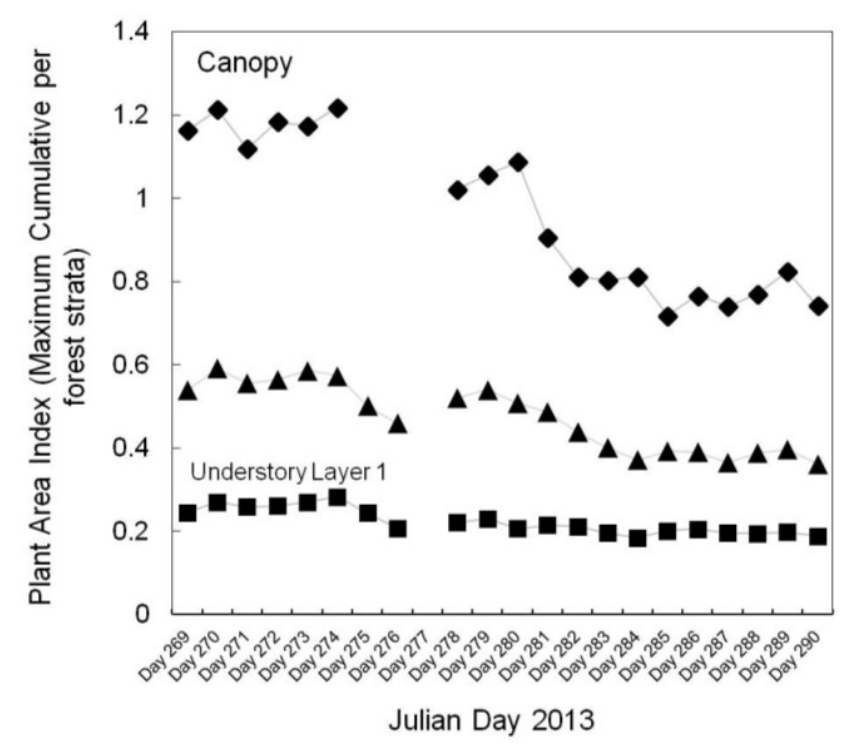

Figure 6. Time-series of Total Plant Area Index (PAI) values calculated by the VEGNET IML during September 26 and October 17, 2013 for the understory, subcanopy (understory layer 2), and Canopy strata.

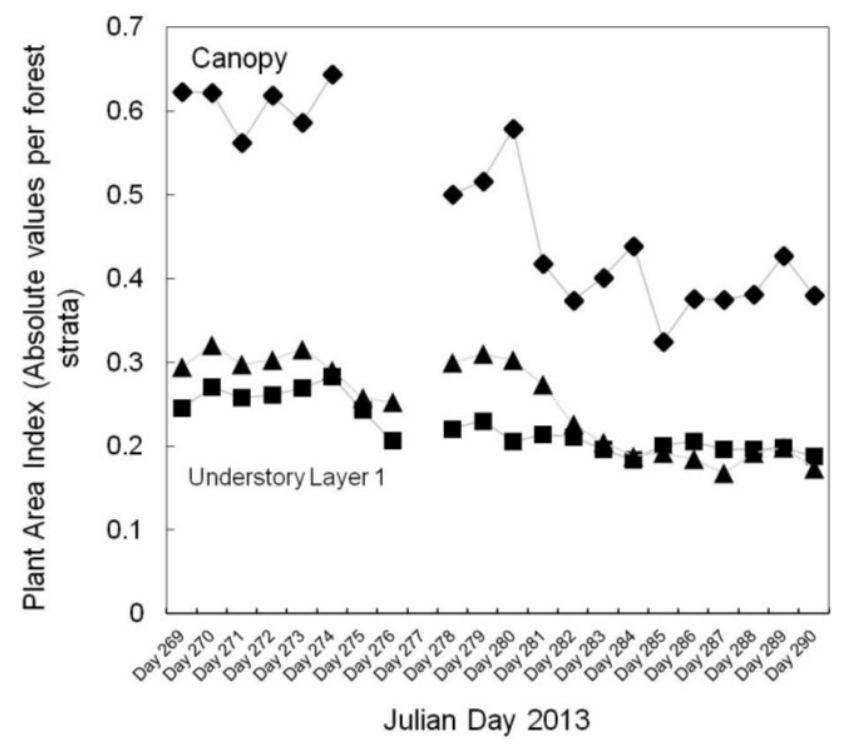


The percentage distribution by different forest strata is shown in Figure 7. Canopy PAI values averaged 0.5 contributing to $50 \%$ of total cumulative PAI of the study site while PAI values from the subcanopy and understory layers averaged 0.2 and 0.3 , contributing to $24 \%$ and $26 \%$ respectively. The percentage contribution by different forest strata to the total maximum cumulative PAI per scan remained similar through the time series with no evidence of increase or decrease in the contribution of one single strata.

Figure 7. Time-series of the percentage contribution of Canopy, Subcanopy (understory layer 2) and understory (understory layer 1) to the maximum cumulative Plant Area Index (PAI) calculated by the VEGNET IML during September 26 and October 17, 2013 for the understory, subcanopy (understory layer 2), and Canopy.

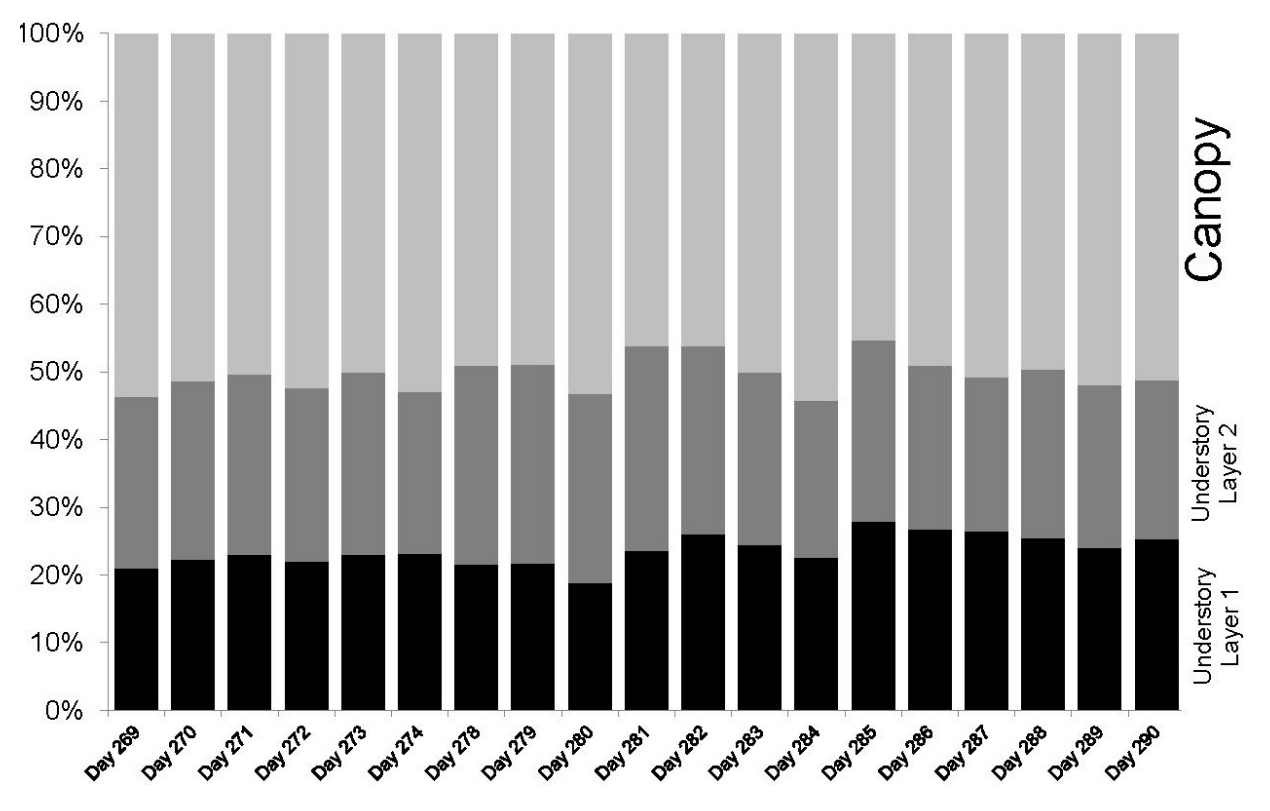

\subsection{Comparison to MODIS 8-Day LAI Product}

Figure 8 shows that MODIS 8-day LAI and IML Maximum Cumulative PAI (averaged for the same 8 -days as the MODIS product) followed a similar decreasing linear trend through time, although the IML cumulative values were $40 \%-48 \%$ higher than MODIS single pixel and $3 \times 3$ window values. Since major refinements of the MODIS LAI product were made from Level-4 to Level-5 (e.g., insertion of a new class representing deciduous forests and its structural attributes with foliage and woody biomass density estimates), we subtracted the effect of understory and subcanopy non-photosynthetic biomass in the assessment and compared MODIS LAI values (which account for woody biomass) to the IML Canopy PAI values (Height zone 14-18 m). As seen in Figure 8, both values not only show a similar decreasing trend but only differed by $2 \%-15 \%$. 
Figure 8. Comparisons of Leaf Area Index values estimated by the MODIS 8-day LAI product vs. Plant Area Index values estimated by the VEGNET IML system.

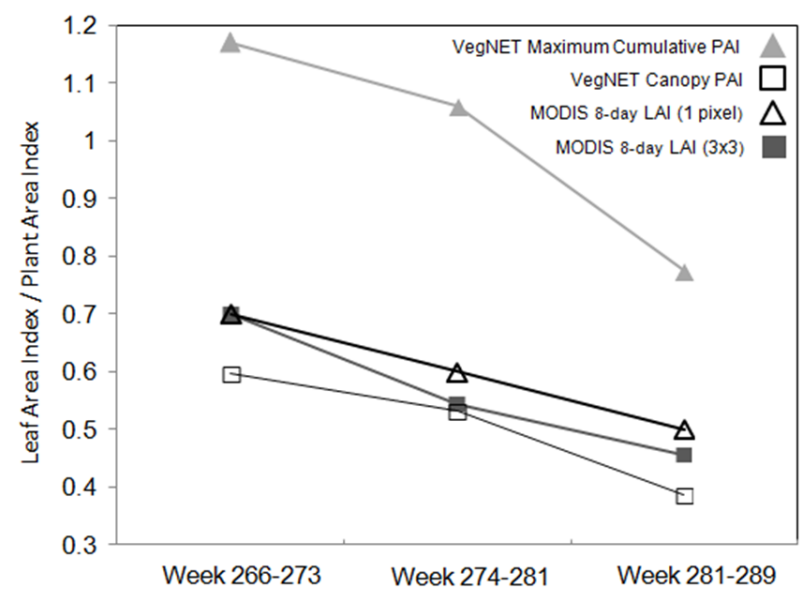

\section{Discussion}

During the implementation of this study, the VEGNET instrument proved to be an autonomous IML system that was easy to set up in the field, physically stable and adapted to endure field conditions. The programming of the device through the microcontroller was simple and straightforward, and its performance during 22 consecutive nights showed satisfactory results. A total of 85 scans were performed, and less than $8 \%$ of the data were excluded because of poor number of records and hits registered as a result of precipitation events that caused condensation on exposed optical surfaces. Based on this, we would expect that the number of discarded scans will increase during seasons with frequent rain and frost in temperate climates. However, the ability to run the instrument during unlimited consecutive nights allows the user to exclude weather-affected scans and still retain sufficient data for detection of forest structural change.

Unfortunately, there are no previous studies on LAI or PAI for the Aspen Parkland forests located at our study site that could be directly compared with the results of this work. However, for Aspen forests in the middle of summer, studies have shown that Plant Area Index values, derived from indirect optical measurements, range from 1.5 to 3 with an average of 2.5 [21]. In the middle of fall (September), PAI values average 1.5 and decrease towards near-zero values in November and December [22]. MODIS 8-day LAI values ranged from 3.5 to 6.5 for the study site during mid-summer 2013 (July) decreasing to 1.6 at the starting week of September 2013. In this study, the highest value of maximum cumulative PAI measured was 1.27 on the Day 269 (September 26), and the lowest maximum cumulative PAI measured was 0.67 on Day 290 (October 17), which are consistent with expected values found in the literature.

The decrease in PAI values registered by the IML instrument during the time of the study was related to the process of leaf-fall in Aspen canopy, understory trees and shrubs during the fall season, as expected. As seen in Figure 2, variability in PAI values was observed between measurements performed in the same night. This variation corresponds to differences in the number of laser measurements and differences in the targets intercepted by the laser which can correspond to a different part of the same branch, trunk or leaf. The random displacement of branches and leaves by 
the wind causes these differences in the targets hit by every scan during the same night of data collection [12].

Studies on the structure and composition of the Aspen Parkland forests in western Canada have described average canopy tree heights of 15-16.4 $\mathrm{m}[23,24]$ and the existence of a canopy, tall shrub and low shrub vegetation strata for this forest type [25]. In the field site, we observed a similar forest structure with a high density of low shrubs and medium density of tall shrubs. The instrument was positioned approximately 20-25 m from a large canopy gap, which increased the amount of understory vegetation towards that part of its field of view.

The IML recorded an average peak in overstorey canopy density at $16.3 \mathrm{~m}$, which fitted within the range of the average tree height reported in previous studies of Aspen parkland forests and our estimates by visual inspection in the field. Average maximum height of a plant element registered by the instrument was $19.1 \pm 0.2$, which represents leaves and/or branches at the top of the canopy. PAVD also peaks at heights of 4 and $6 \mathrm{~m}$, corresponding to Low shrubs (understory layer I) and Tall shrubs (understory layer II), respectively. We estimate that hits were registered from understory vegetation concentrated about $2-6 \mathrm{~m}$ around the instrument's position. Understory vegetation at these heights corresponded to the sum of low and tall shrub biomass (leaves and branches) and trunks of canopy trees. PAVD values registered around heights of 8-12 m corresponded mostly to trunk biomass of canopy trees, and less to photosynthetic biomass. This is particularly evidenced by low and stable PAVD values through the time-series at these heights.

Phenological changes during the time of data collection were captured in four ways: number of hits, maximum cumulative and absolute PAI values, time series of PAVD profiles and PAI values per forest strata. The ability to extract PAI values per height or height range using the IML data allows for a better understanding of the contribution of each forest stratum to the maximum cumulative PAI. Differences in trends in PAI and PAVD values observed for the canopy, understory layer I and understory layer II were registered by the instrument. While both canopy and understory layer II show a continuous decrease of PAI and PAVD values, the understory layer I does not show strong changes with time. This is expected since there is a higher component of woody biomass from understory vegetation and trunks of canopy trees in the lower forest stratum.

The comparison to MODIS 8-day LAI at $1 \mathrm{~km}$ spatial resolution showed interesting results. In order to subtract the effect of adding understory and subcanopy non-photosynthetic biomass, we compared MODIS LAI values (single pixel and $3 \times 3$ window mean) to the IML PAI values only for the Canopy height zone (14-18 m). In this case, both values not only show a similar decreasing trend but only differed by $2 \%-15 \%$, in contrast to the $48 \%$ difference to IML maximum cumulative values.

We can infer that patchy distribution of understory biomass in the area, as well as the presence of linear openings and small ponds at the landscape level yielded lower LAI values at 1-km resolution, however, MODIS LAI retrieval algorithms have included corrections to subtract woody area index from total LAI estimation for each forest type, including broadleaf deciduous forests. The exclusion of understory vegetation from ground PAI estimation might have leveled out the comparison, therefore, allowing IML Canopy PAI to resemble expected LAI values for this forest type. Given the potential of using an IML system to validate spaceborne LAI products, future research should be made to investigate how IML PAI values compare to indirect optical and satellite-based measurements during a longer 
period of time, and whether the calculation of IML Canopy PAI resembles actual LAI estimates for Aspen Parkland forests or other vegetation types.

\section{Conclusions}

The use of ceptometers and digital hemispherical photographs to estimate Plant Area Index often include biases and errors from instrument positioning and orientation in the field or from differences in thresholding to the optimal brightness level during the generation of the binary image (1). However, LAI retrieval from these techniques remain a common practice in forestry and ecology; especially, since recent research has attempted to improve its PAI estimates through a better description and sampling of canopy heterogeneity (vertical and horizontal heterogeneity, clumping, canopy closure or gaps) [11]. These methods are also part of the standard validation methods of remotely-sensed LAI products [19,26]. However, there has been an increase in research applied to the use of TLS systems as alternative methods to measure PAI and LAI. Multi-angular techniques such as terrestrial laser scanners (TLS) allow a more detailed and accurate exploration of foliage angle distributions and clumping that can help to resolve aspects of the foliage profile that are not fully addressed by other indirect methods.

As Breda et al. [11] suggests, the main challenging point to improve LAI measurement is to identify clearly the causes of its variation. The ability to track changes of PAI or LAI on a daily basis during extended periods of time can allow the identification of physiological triggers and/or structural effects on LAI estimates. The VEGNET system used in this study, proved to be an autonomous IML system that was easy to set up in the field, physically stable and adapted to endure field conditions. The instrument captured maximum cumulative and vertical distribution of PAI consistent with estimates found in the literature for the region and other MODIS LAI estimates. It was able to collect daily data without the need for frequent visits to the field. As an alternative to other TLS instruments, the IML system has the potential of providing useful and consistent data for structural and phenological studies at lower cost because it does not include vertical scanning functionality. The system is suitable for medium to long term forest monitoring studies at a "plot" scale, where the plot radius is approximately twice the canopy height. Although the system captures relatively little spatial detail, the small data volume is suitable for wireless transmission to a data aggregator, which can send data to the user's computer via cell-modem communications. Such characteristics are advantageous especially since there is a need to explore hypertemporal information in real time to improve the effectiveness of decisions for researchers (during data collection seasons) and environmental managers.

More studies are needed in order to validate the IML maximum cumulative PAI, and total PAI values at different heights. This must be done by comparing its measurements to actual values of LAI (direct methods) and indirect estimates (digital hemispherical photographs, ceptometers and TLS systems). Studies should include tests of its performance in different forest types, successional stages and disturbance scenarios.

\section{Acknowledgments}

This work was supported in part by a TecTerra grant 1209-UNI-013. Access to the study site was provided by the Alberta Environment and Sustainable Resource Development (ESRD). We would like to thank the logistic support from Dr. Shane Patterson from ESRD, and the help from Cassidy Rankine 
and Cao Sen (University of Alberta) during fieldwork. We acknowledge the University of Alberta for logistical support.

\section{Author Contributions}

Carlos Portillo-Quintero and Arturo Sanchez-Azofeifa conceived the work, designed the instrument's deployment in the field and performed the data analysis. Carlos Portillo-Quintero carried out the fieldwork and data analysis. Darius Culvenor developed and designed the instrument and supervised the instrument's performance. All three authors contributed to the written content of the manuscript.

\section{Conflicts of Interest}

The authors declare no conflict of interest.

\section{References}

1. Jonckheere, I.; Fleck, S.; Nackaerts, K.; Muys, B.; Coppin, P.; Weiss, M.; Baret, F. Review of methods for in situ leaf area index determination: Part I. Theories, sensors and hemispherical photography. Agric. For. Meteorol. 2004, 121, 19-35.

2. Francone, C.; Pagani, V.; Foi, M.; Cappelli, G.; Confalonieri, R. Comparison of leaf area index estimates by ceptometer and PocketLAI smart app in canopies with different structures. Field Crop. Res. 2014, 155, 38-41.

3. Lovell, J.L.; Jupp, D.L.; Culvenor, D.S.; Coops, N.C. Using airborne and ground-based ranging lidar to measure canopy structure in Australian forests. Can. J. Remote Sens. 2003, 29, 607-622.

4. Watson, D.J. Comparative physiological studies on the growth of field crops: II. The effect of varying nutrient supply on net assimilation rate and leaf area. Ann. Bot. 1947, 11, 375-407.

5. Fournier, R.A.; Mailly, D.; Walter, J.M.N.; Soudani, K. Indirect measurement of forest canopy structure from in situ optical sensors. In Remote Sensing of Forest Environments; Springer US: New York, NY, USA, 2003; pp. 77-113.

6. Stone, C.; Coops, N.; Culvenor, D. Conceptual development of a Eucalypt canopy condition Index using high resolution spatial and spectral remote sensing imagery. J. Sustain. For. 2000, 11, 23-45.

7. Kalacska, M.E.; Sánchez-Azofeifa, G.A.; Calvo-Alvarado, J.C.; Rivard, B.; Quesada, M. Effects of season and successional stage on Leaf Area Index and Spectral Vegetation Indices in three mesoamerican tropical dry forests. Biotropica 2005, 37, 486-496.

8. Menzel, A. Phenology: Its importance to the global change community. Clim. Chang. 2002, 54, 379-385.

9. Cleland, E.E.; Chuine, I.; Menzel, A.; Mooney, H.A.; Schwartz, M.D. Shifting plant phenology in response to global change. Trends Ecol. Evol. 2007, 22, 357-365.

10. Krishnaswamy, J.; John, R.; Joseph, S. Consistent response of vegetation dynamics to recent climate change in tropical mountain regions. Glob. Chang. Biol. 2014, 20, 203-215. 
11. Bréda, N.J. Ground-based measurements of leaf area index: A review of methods, instruments and current controversies. J. Exp. Bot. 2003, 54, 2403-2417.

12. Beland, M.; Baldocchi, D.D.; Widlowski, J.L.; Fournier, R.A.; Verstraete, M.M. On seeing the wood from the leaves and the role of voxel size in determining leaf area distribution of forests with terrestrial LiDAR. Agric. For. Meteorol. 2014, 184, 82-97.

13. Strahler, A.H.; Jupp, D.L.; Woodcock, C.E.; Schaaf, C.B.; Yao, T.; Zhao, F.; Yang, X.; Lovell, J.; Culvenor, D.; Newnham, G.; et al. Retrieval of forest structural parameters using a ground-based lidar instrument (Echidna ${ }^{\circledR}$ ). Can. J. Remote Sens. 2008, 34, S426-S440.

14. Clawges, R.; Vierling, L.; Calhoon, M.; Toomey, M. Use of a ground-based scanning LiDAR for estimation of biophysical properties of western larch (Larix occidentalis). Int. J. Remote Sens. 2007, 28, 4331-4344.

15. Jupp, D.L.; Culvenor, D.S.; Lovell, J.L.; Newnham, G.J.; Strahler, A.H.; Woodcock, C.E. Estimating forest LAI profiles and structural parameters using a ground-based laser called 'Echidna ${ }^{\circledR}$. Tree Physiol. 2009, 29, 171-181.

16. Little, L.R.; Dale, M.R.T. A method for analysing spatio-temporal pattern in plant establishment, tested on a Populus balsamifera clone. J. Ecol. 1999, 87, 620-627.

17. Donkor, N.T.; Okello, M.M.; Hudson, R.J.; Bork, E.W. Seasonal dynamics and defoliation impact on herbage yield in aspen boreal habitats of Alberta. Can. Field-Nat. 2003, 117, 196-202.

18. Warren-Wilson, J. Estimation of foliage denseness and foliage angle by inclined point quadrats. Aust. J. Bot. 1963, 11, 95-105.

19. De Kauwe, M.G.; Disney, M.I.; Quaife, T.; Lewis, P.; Williams, M. An assessment of the MODIS collection 5 leaf area index product for a region of mixed coniferous forest. Remote Sens. Environ. 2011, 115, 767-780.

20. Available online: www.agric.gov.ab.ca (accessed on 20 January 2014)

21. Chen, J.M.; Rich, P.M.; Gower, S.T.; Norman, J.M.; Plummer, S. Leaf area index of boreal forests: Theory, techniques, and measurements. J. Geophys. Res. 1997, 102, 29429-29443.

22. Barr, A.G.; Black, T.A.; Hogg, E.H.; Kljun, N.; Morgenstern, K.; Nesic, Z. Inter-annual variability in the leaf area index of a boreal aspen-hazelnut forest in relation to net ecosystem production. Agric. For. Meteorol. 2004, 126, 237-255.

23. Hogg, E.H.; Hurdle, P.A. The aspen parkland in western Canada: A dry-climate analogue for the future boreal forest? In Boreal Forests and Global Change; Springer Netherlands: Edmonton, Canada, 1995; pp. 391-400.

24. Brandt, J.P.; Cerezke, H.F.; Mallett, K.I.; Volney, W.J.A.; Weber, J.D. Factors affecting trembling aspen (Populus tremuloides Michx.) health in the boreal forest of Alberta, Saskatchewan, and Manitoba, Canada. For. Ecol. Manag. 2003, 178, 287-300.

25. Bork, E.W.; Hudson, R.J.; Bailey, A.W. Upland plant community classification in Elk Island National Park, Alberta, Canada, using disturbance history and physical site factors. Plant Ecol. 1997, 130, 171-190. 
26. Morisette, J.T.; Baret, F.; Privette, J.L.; Myneni, R.B.; Nickeson, J.E.; Garrigues, S.; Cook, R. Validation of global moderate-resolution LAI products: A framework proposed within the CEOS land product validation subgroup. Geosci. Remote Sens. IEEE Trans. 2006, 44, 1804-1817.

(C) 2014 by the authors; licensee MDPI, Basel, Switzerland. This article is an open access article distributed under the terms and conditions of the Creative Commons Attribution license (http://creativecommons.org/licenses/by/3.0/). 